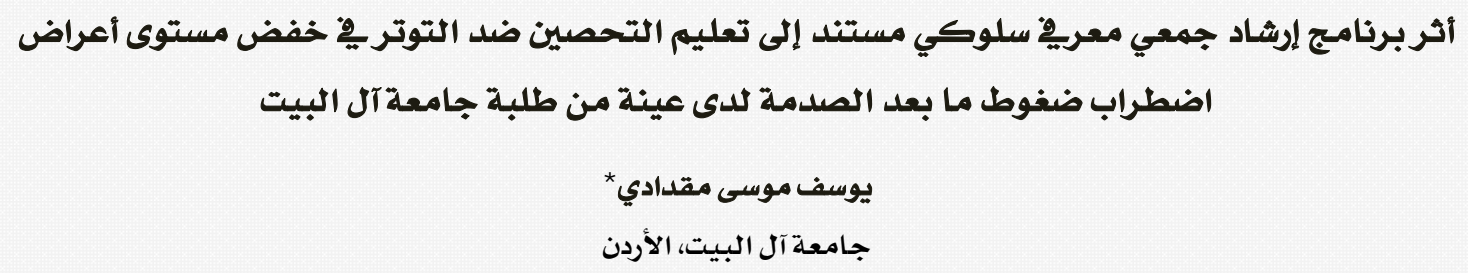

هدفت الدراسة إلى التعرف إلى أثر برنامج إرشاد جمعي معربِّ سلوكي مستتد إلى تعليم التحصين ضد التوتر ِِّ خفض

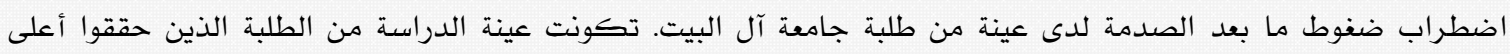
الدرجات على مقياس اضطراب ضغوط ما بعد الصدمة، والبالغ عددهم 17 طالباً. تم توزيع الأفراد عشوائياً إلى مجموعتين:

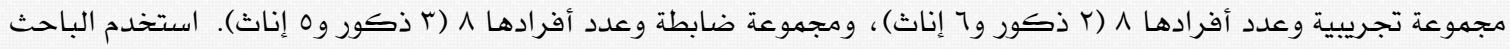

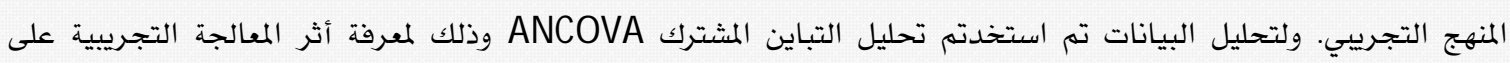

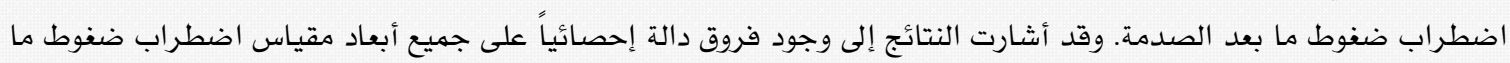

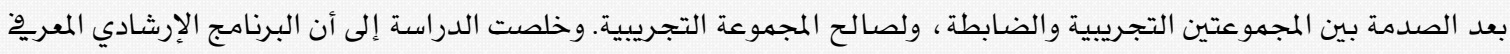

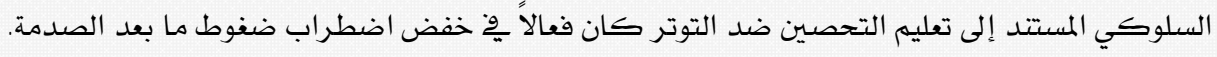
الكلمات المفتاحية: اضطراب ضغوط ما بعد الصدمة ، التحصين ضد التوتر ، الإرشاد الجمعي.

\title{
The Impact of a Cognitive Behavioral G roup Counseling Program Based on Stress Inoculation Training on Reducing Posttraumatic Stress among a Sample of Students from Al al-Bayt University
}

Yusef M. Migdady

Al al-Bayt University, Jordan

The aim of this study was to examine the impact of a cognitive behavioral group counseling program based on stress inoculation training in reducing post-traumatic stress among a sample of students from Al al-Bayt University. The sample of the study consisted of 16 students who achieved the highest score on a scale for post-traumatic stress disorder. These students were distributed randomly into two groups: experimental group consisting of 8 students ( 2 males and 6 females) and a control group consisting of 8 students ( 3 males and 5 females). The researcher used the experimental method; the application of the program took four weeks with two meetings per week. Analysis of covariance (ANCOVA) was used to know the experimental treatment effect on post-traumatic stress. The results showed statistically significant differences between the experimental and control groups, favoring the experimental group, on all dimensions of the scale. The study concluded that the counseling program -based on stress inoculation training- was effective in reducing post-traumatic stress.

Keywords: post-traumatic stress disorder, stress inoculation, group counseling. 


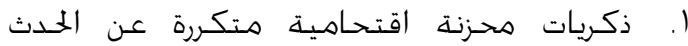

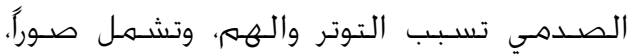
وأفكارًا، وهـدركات.

ז. أحلام مـزعجـة ومتكررة عـن الحدث الصـدمي.

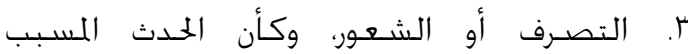
للصـدمة يعاود الوقوع. لتصن.

ك. انزعاج نفسي حاد عند التعرض لمثيرات داخلية أو خارجيـة.

0. استجابة فسيولوجية عند التعرض لمثيرات

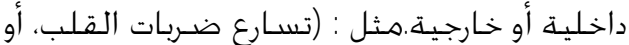

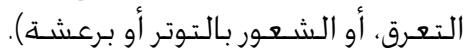
ثالثًا: كما أن المصابين باضـطراب (PTSD) يتميزون

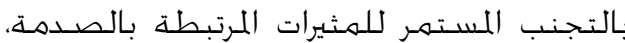

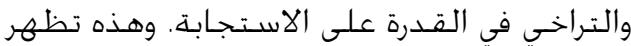

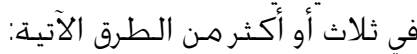
ا. بذل الجهود لتجـنب الأفكار، والمشـاعر، والأحاديث

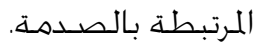

أ. بـل الجهود لتجنب الأنشـطة، أو الأماكن، أو

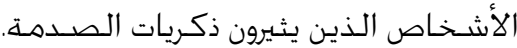

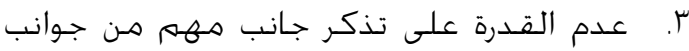

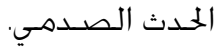

ع. ابتعاد ملحوظ عن الاهتعمام أو المشاركة في الأنشـطة المهـمة ملحوف.

0. الشـعور بالانفصـال عن الآخرين، أو الغربة عنهمه. 1. قصـور في المشـاعر الوجـدانية، هثل: عدم القـدرة على الشـعور بالخب. V الإحسـاس بغمهوض المستقبل، مثل: فقـدان الأمل

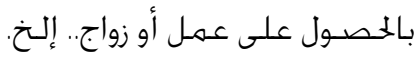

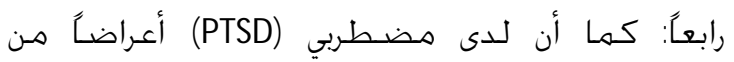

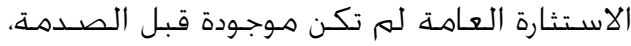
وتتضـح في اثنـين أو أكثر مما يأتي :

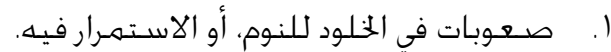
ז. الاسـتثارة (الهيجان)، أو نوبات الغضـب.

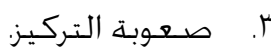

ع. التيقظ الشـديد (حسـاسية ونشاط مفرط وخَفز). 0. استجابة جفلة مبالغ فيها (جفلة مفرطة عند

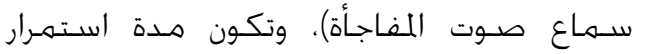

إن اضطراب ضغوط ما بعد الصـدمة Posttraumatic Stress Disorder ; PTSD

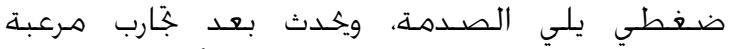

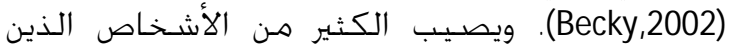

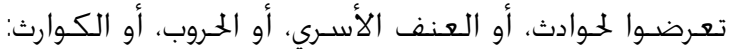

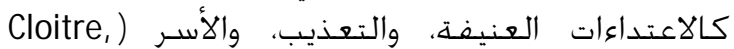

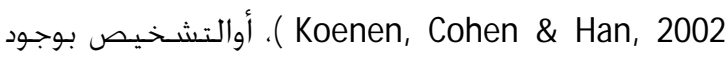
مرض خطير أو مشـاهدة أحداث مفجعة، أو العلم

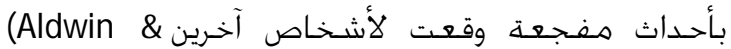

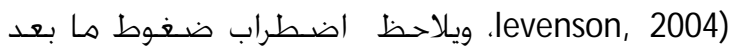

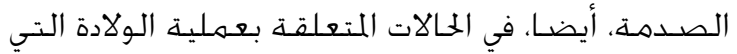

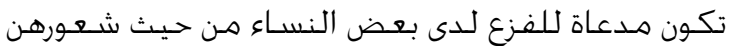

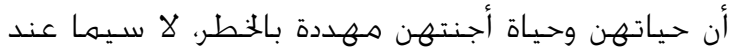

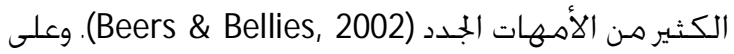

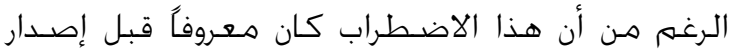

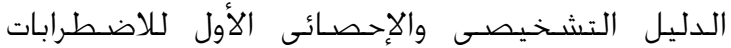

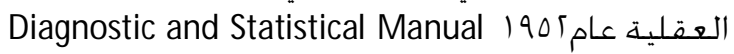
of Mental Disorder

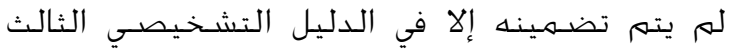
(March,1998) (MA • عام (DSM -III)

وحهول انتشـار اضـطراب ضغوط ما بعـد الصـدمة

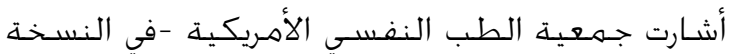

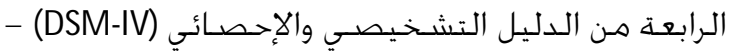

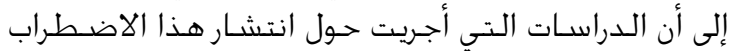

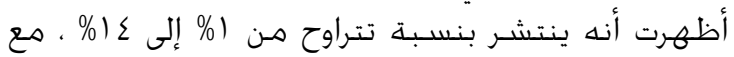

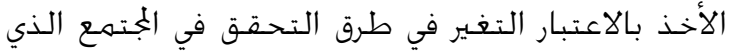

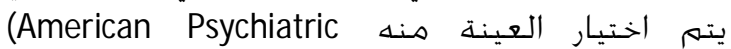
.Association, 1994)

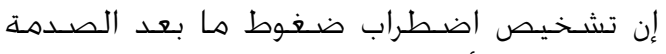

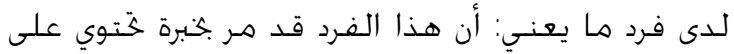

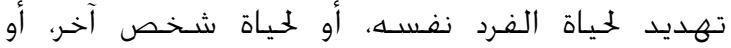

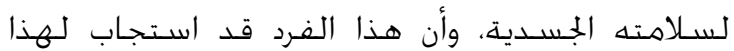

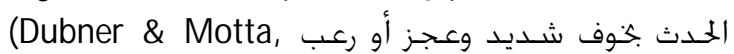

.1999)

وبكسـب تصنيف (DSM-IV-R, 94) فإن الحادث الصـادم يشترط فيه توافر المعايير الآتية:

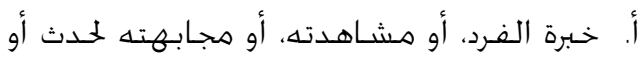

أوكاً:

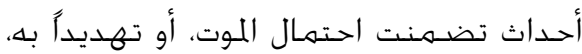

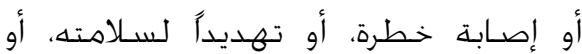

سـلاهـ الآخرين الجسـدية.

ب. رد فعل الفـرد، يتسـم بالخوف الشـديد، أو العجزن.

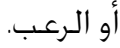

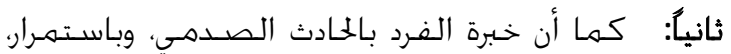

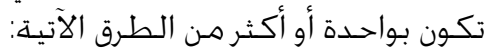


وكيفية مواجهتها، وتوفير المسـاندة للفئات الأكثر عرضـة

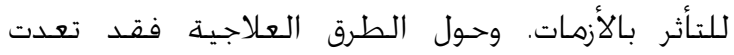

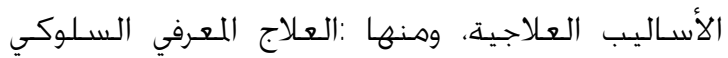
Behavior Therapy Cognitive

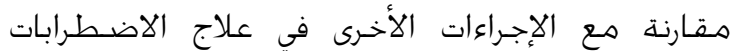
النفسية \& Yeong \& Chia, 2001, Murphy, Lehrer Jurish, 1990; Nicholson \& Blanchard, 1993; Gagnon \& Ladouceur, 1992)

و يعد العلاج المعرفي السلوكي محاولة هادفة

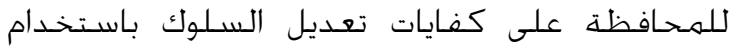

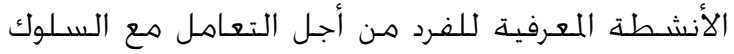
(Hollan \& Rendall, 1996) Methodological Behaviorism

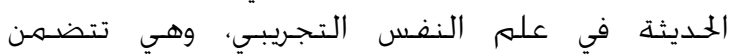

الأسـاليب المعرفية والسـلوكية معاً (Hunter, 2003).

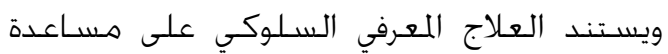

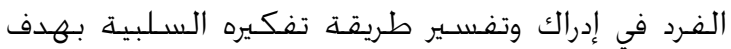
تغيرها إلى أفكار أو قناعات ايجابية أكثر واقعية. ويهدف

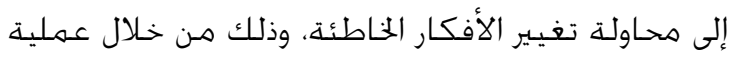

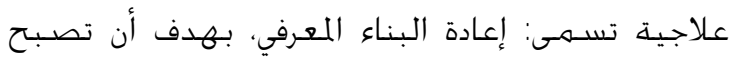

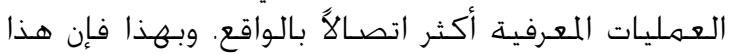

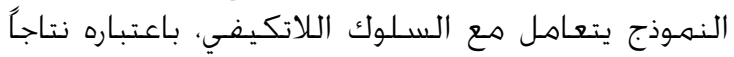

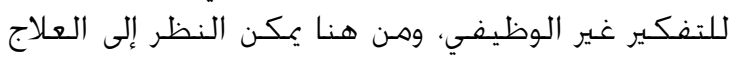

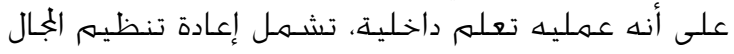

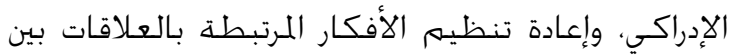

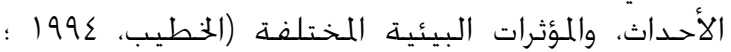

.). Hersen \& Bellck, 1985

والتحصين ضـــ التوتر Stress Inoculation أسـلوب

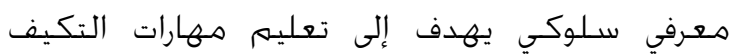

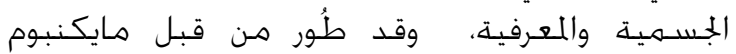
وكاميرون (Meichenbaum \& Cameron) لمسـاعدة الأفراد الذين لديهم ردود أفعال ناجتة عن الخهوف المرضي.

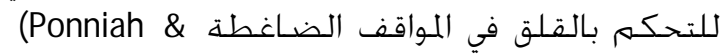
Hollon, 2009)

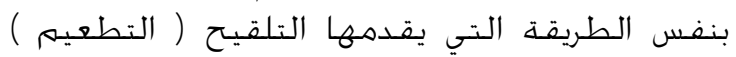

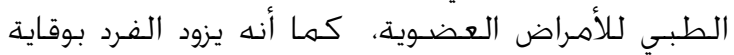

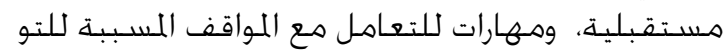

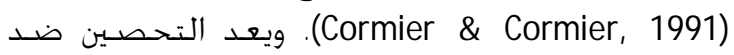

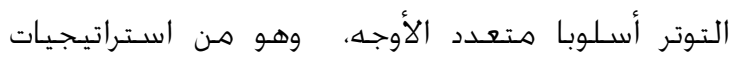

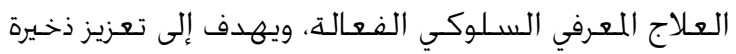

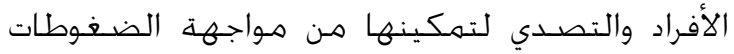
وتبني مهارات التكيف (Meichenbaum, 1996).

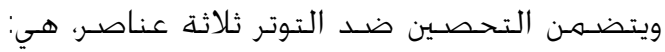
1 - تعليم الفرد وتثقيفه حول طبيعة التهن ردود الأفعال الناجتة عن التوتر ؟ - تدريب الفرد على مهارات التكيف الجسبـدية
الاضطراب وفقًاً للمعايير (ثانياً / ثالثًاً رابعاً)

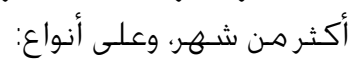

- اضطراب ما بعد الصـدمة النفسية الخاد (Acutc-PTSD)

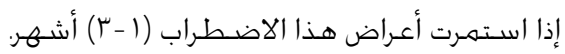

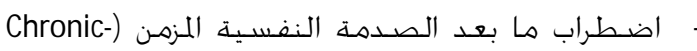

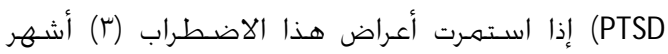
فأكثر.

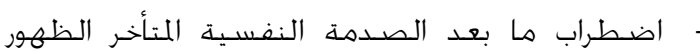
إذا ظهرت علامات الاضطراب بعد المتاخد الخهر (Delayed - PTSD) سـتة أشهر، ولم تظهر قبلها.

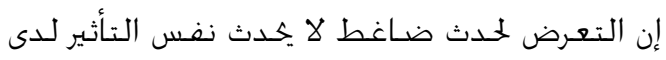

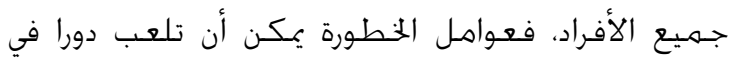

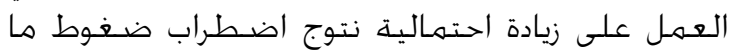

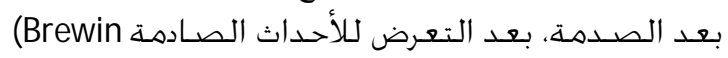
ت ف Holmes, 2003)

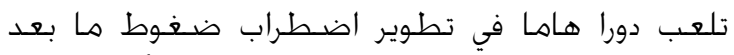

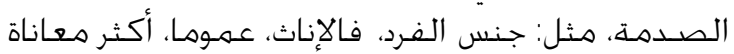

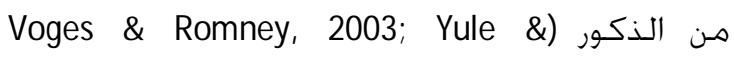
مُ هما أن أعراض اضطراب ضغوط \& (Canterbury, 1999,

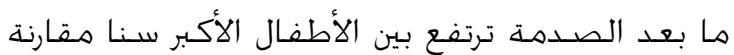

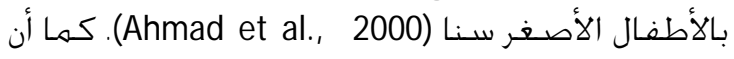

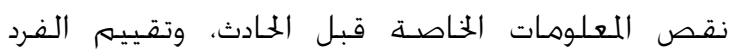

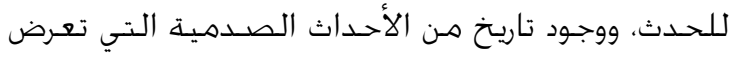

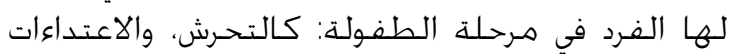

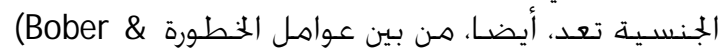

.Regehr, 2006)

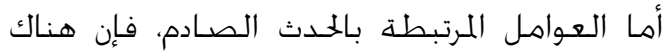

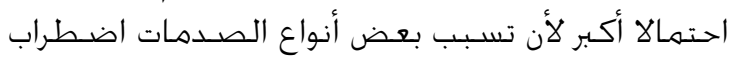
ضغوط ما بعد الصـدمة أكثر من أنساع النواع أخرى.

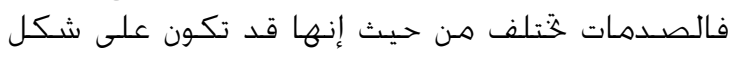

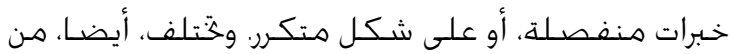
حيث شـاتها ونوعيتها (Tucker \& Trautman, 2000).

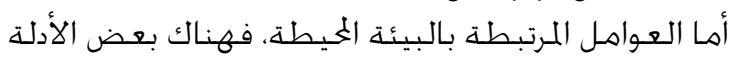

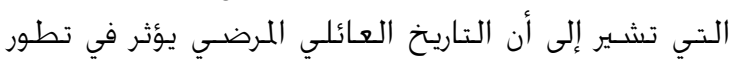

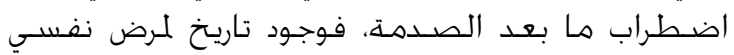

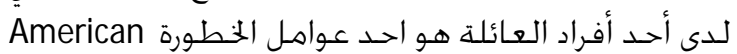

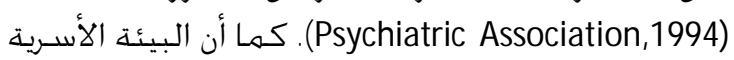

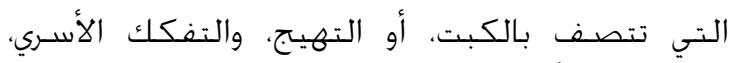

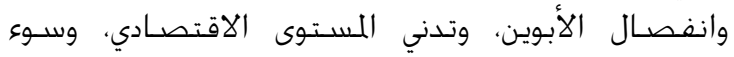

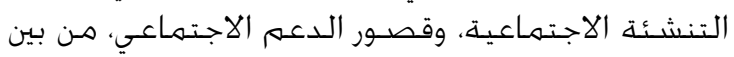

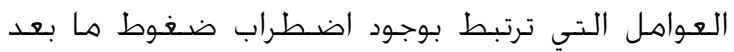

الصـدمة (Becky, 2002, Brewin \& Holmes, 2003).

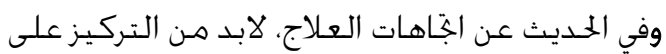

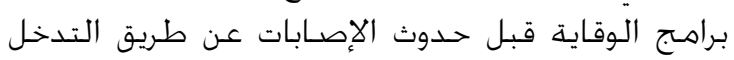

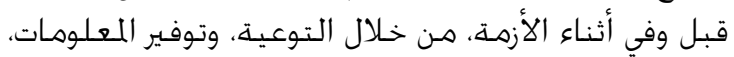


الصدمة لضحايا الاعتداء من النساءوتم تطبيق العلاج

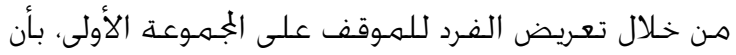

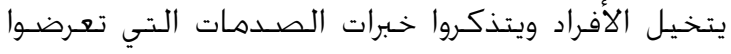

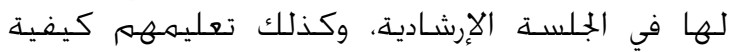

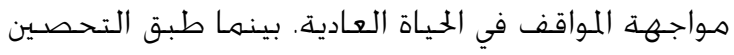

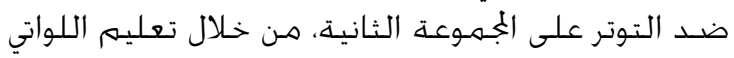

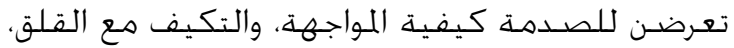

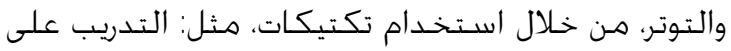

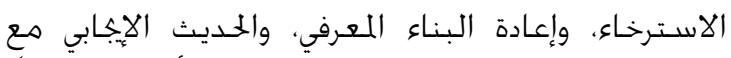

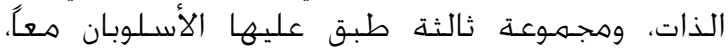

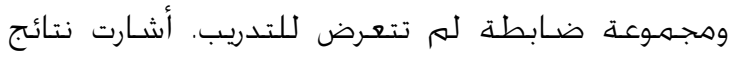

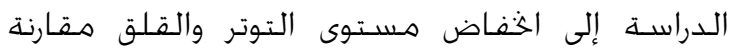

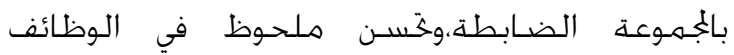

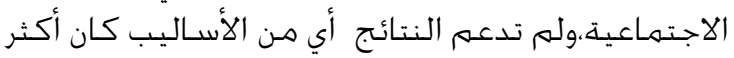
فاعلية.

وقام هانز (Hains,1992) بدراسـة هدفت للتعرف

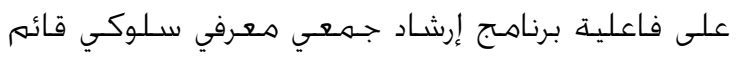

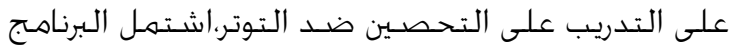

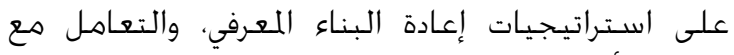

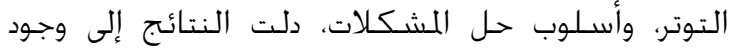

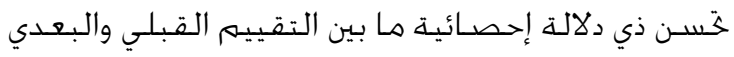

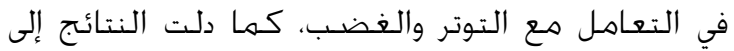

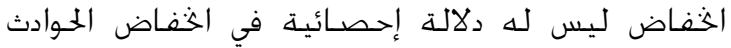
الضـاغطة، وله يحدث تغيير على حالات الاكتئاب، وتقدير الخاضير

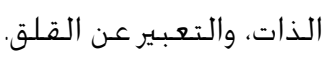

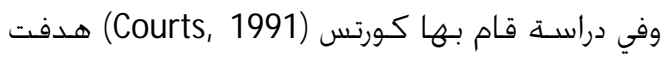

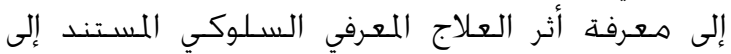

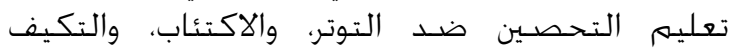

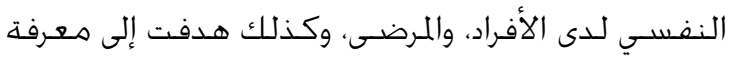

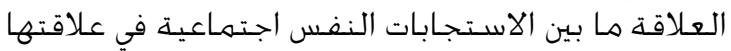

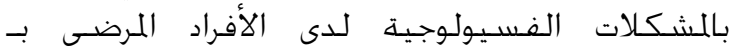
Hemodialysis

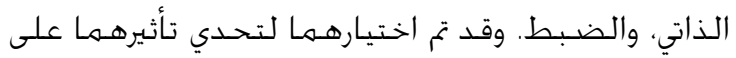

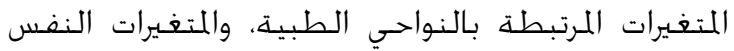

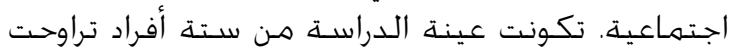

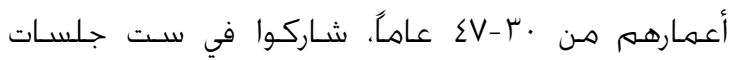

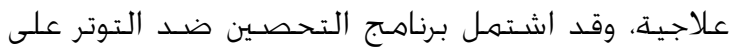

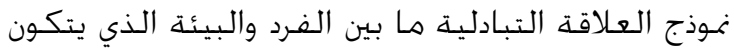

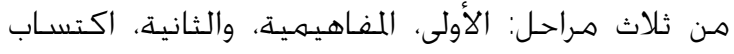

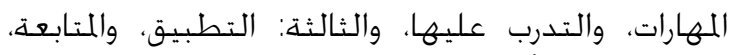

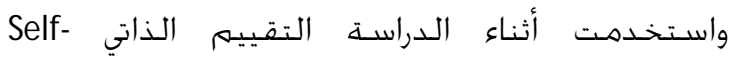

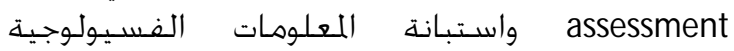
وأشارت النتائج إلى أن البرنامج Physiological Data

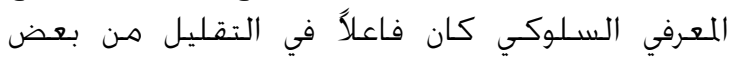

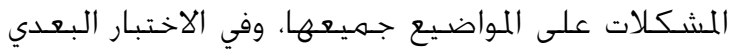

والمعرفية بر - مساعدة الفرد على تطبيق هذه المهارات

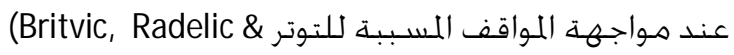
Urlic, 2006)

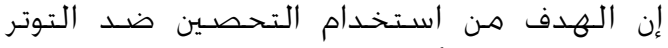

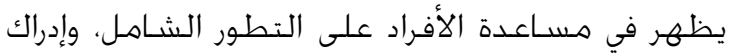

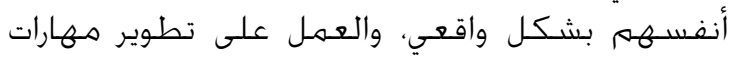
المواجهة، واكتساب الجاهات تكيفيه لضغولئ لضوطات الحياة

.(Hans, 1992)

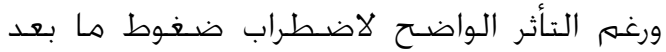

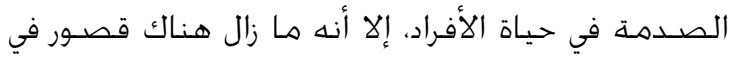

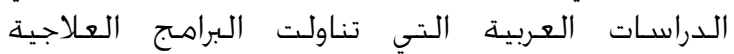

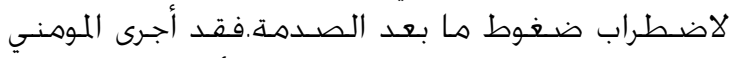

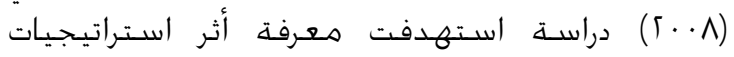

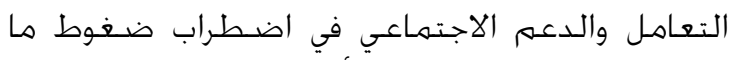

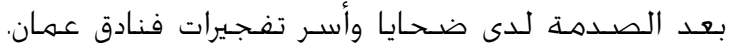

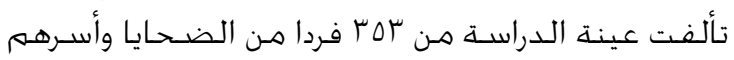

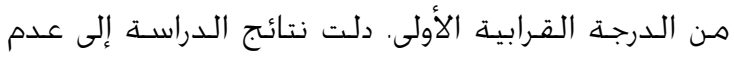

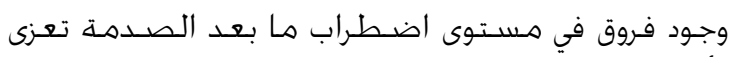

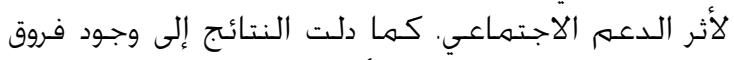

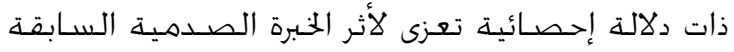
والجنس ولصالح الإناث والتدين ولصالح شـديدي التدين.

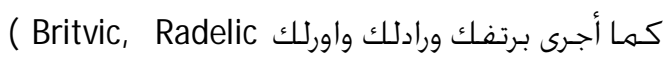
\& Urlic, 2006)

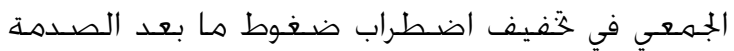

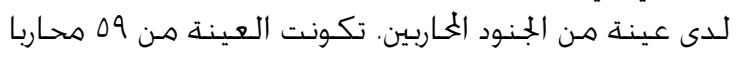

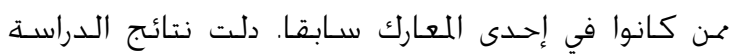

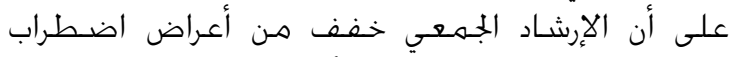
ضغوط ما بعد الصـدمة لدى أفراد العينة.

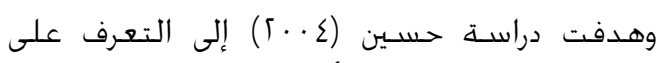

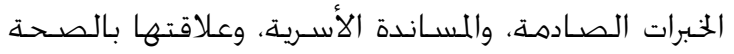

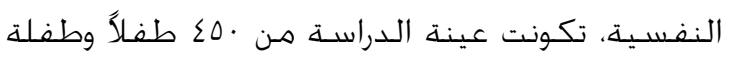

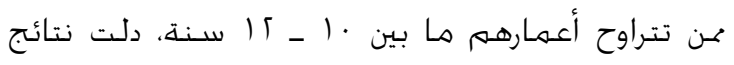

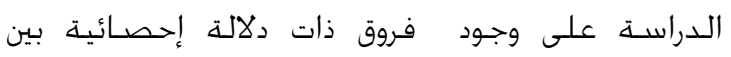
الأطفال الذين تلقوا مساندة أسـرية كبيرة، والأطفال

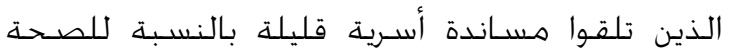

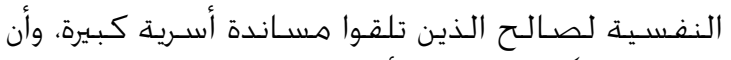

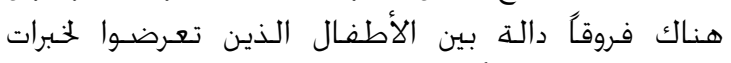

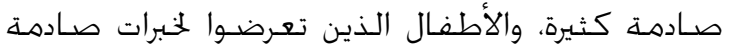

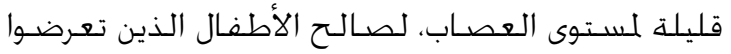
لخبرات صـادمة كثيرة.

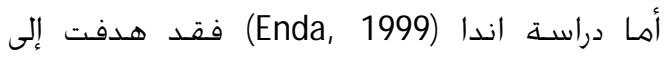

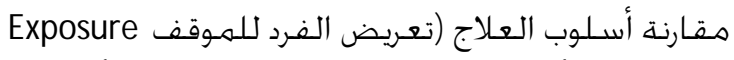
(Therapy

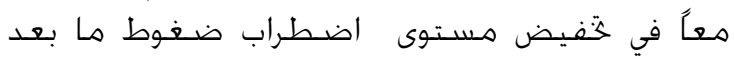


(991) إلى إن معالجة أحداث الحياة الضـاغطة لا تعنى

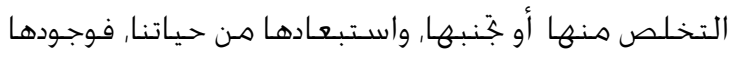

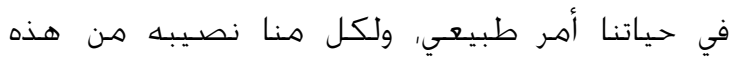
الأحّداث اليومية بدرجات متفاوتة, ووجودها لا لا يعنى أننا

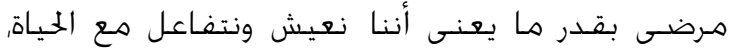

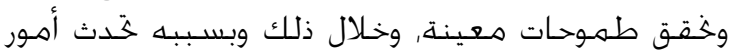

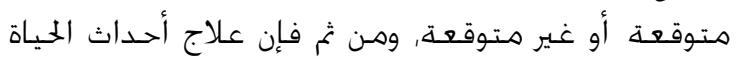

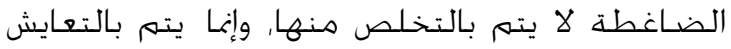
الايمابي معهار ومعالجة نتائجها السـلبية.

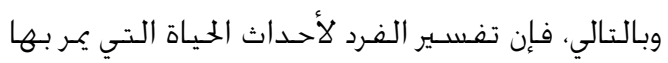

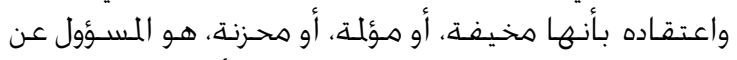

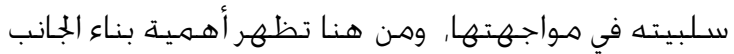

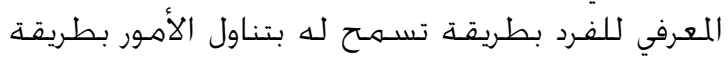

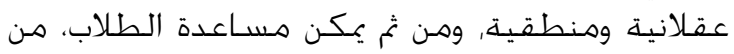

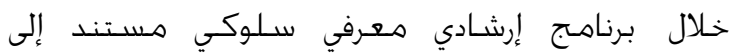

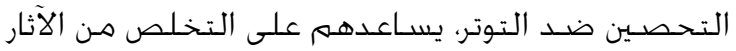
السـلبية لاضطراب ضغوط ما بعد الصـدمة.

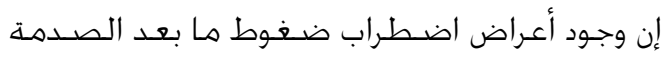

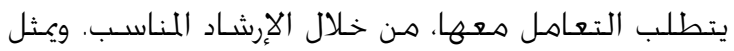

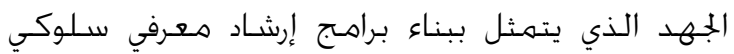

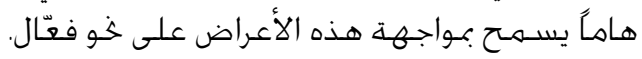

\section{سؤال الدراسة: - n}

تســهدف هذه الدراسـة الإجـابة على السؤوال التالي:

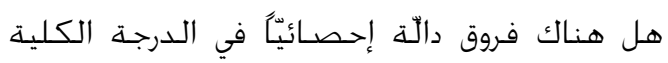

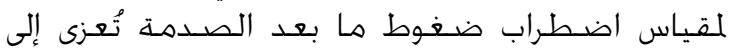

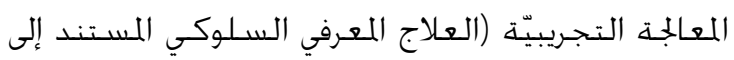

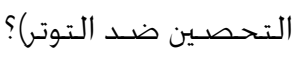

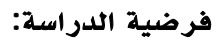

بنيت الدراسـة الحالية على الفرضية التالية:

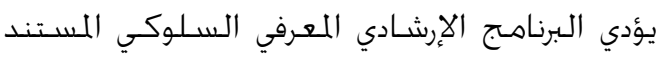

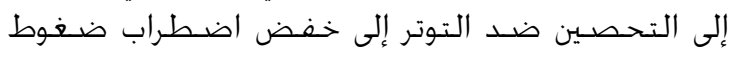

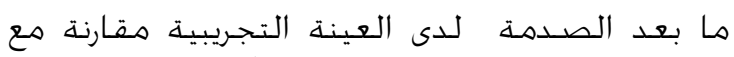

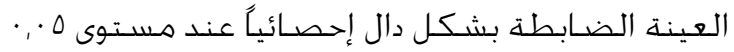

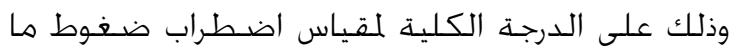
بعد الصـدمة.

\section{أهمية الدراسة: - |}

ترجع أهمية الدراسـة الحالية إلى ما يلي:

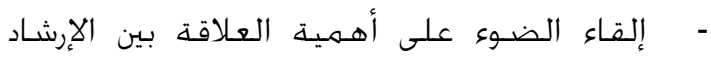

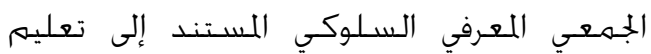

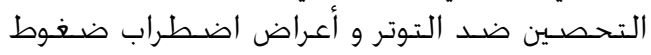

تبين اخففاض مستوى القلق عند جميع المشاركين، فيما

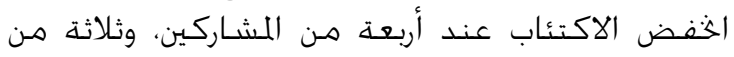

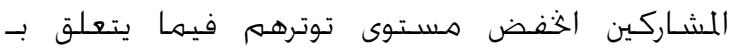
Hemodialysis التكيف النفس -اجتماعي مع المرض.

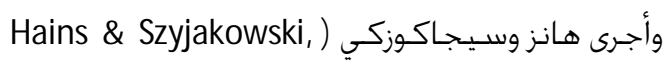

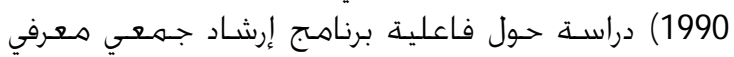

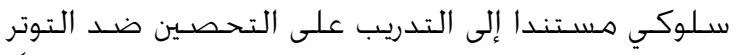

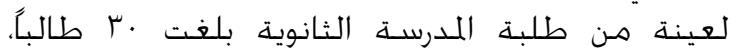

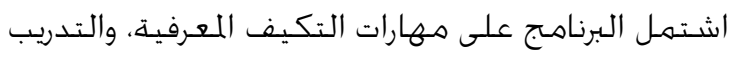

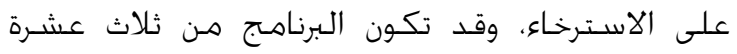
جلسة مؤلفة من ثلاث مراحل هي: مرحلة الآلة المفاهيم.

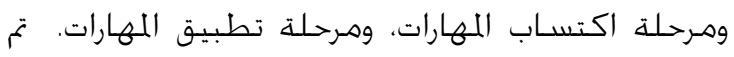

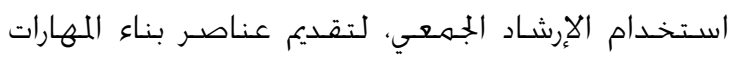

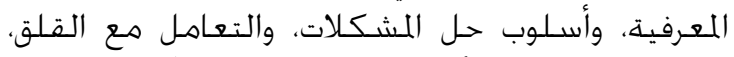

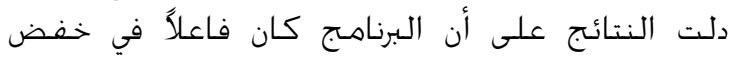

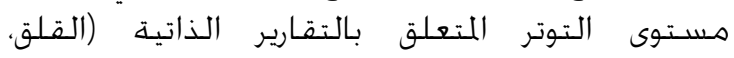

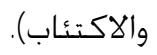

يتضح من الدراسـات السابقة فاعلية الإرشاد

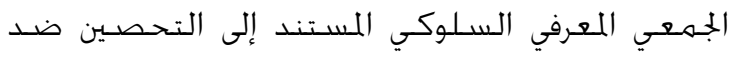

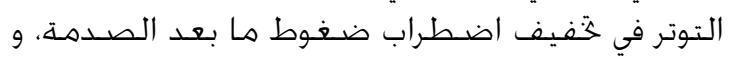

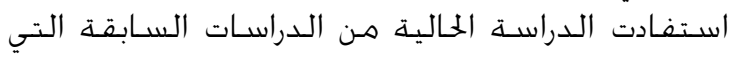
اعتمدت في تصميمها التجريبي على لـالى مجموعتين: أحداهـما, جُريبية, والأخرى ضـابطة.

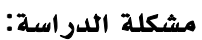

ختل الضغوط النفسية في الآونة الأخيرة مكانها

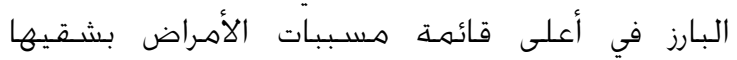

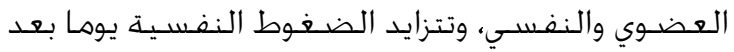

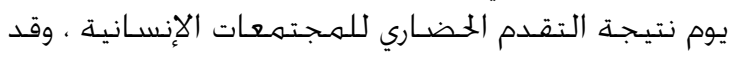

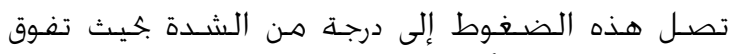

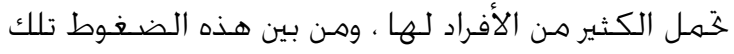

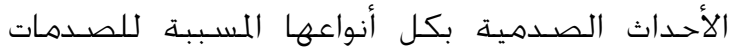

النفسـيـة.

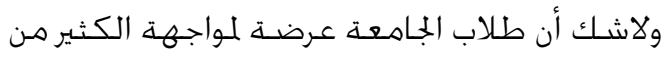

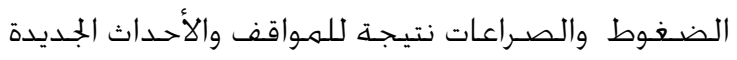

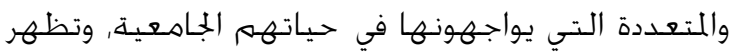

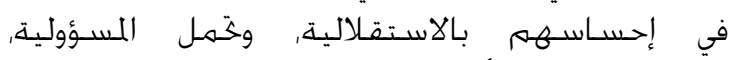

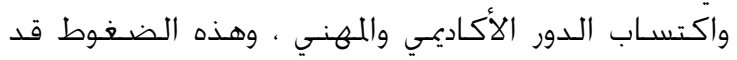
تدفعهم إلى الوقوع في العديد من المشكيلات النفسية.

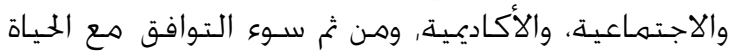
الجامعية.

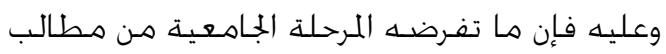

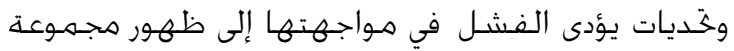

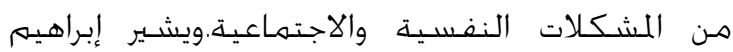




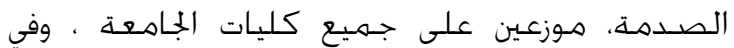

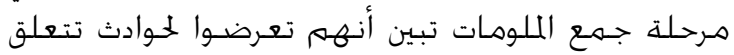

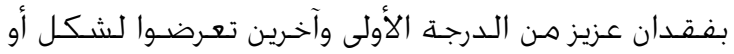

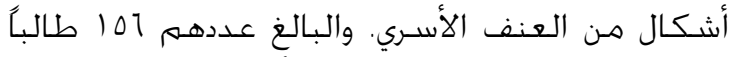

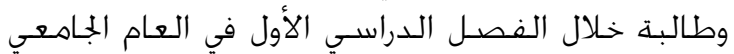

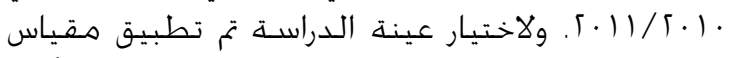

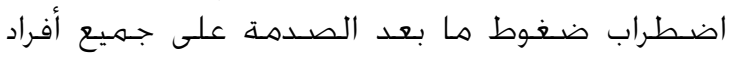

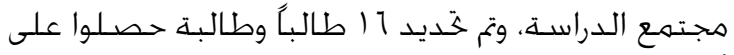

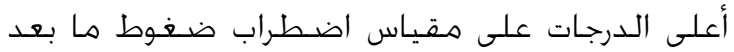

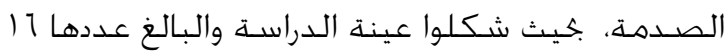

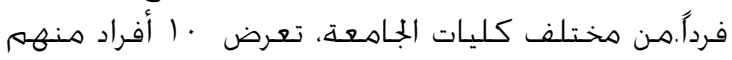

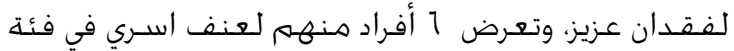

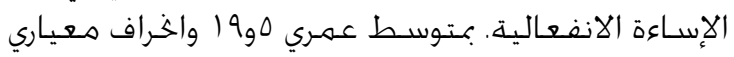

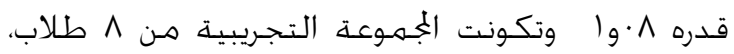

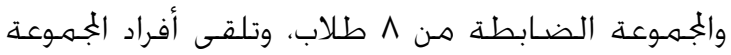

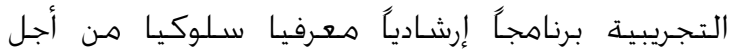

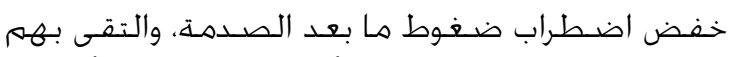

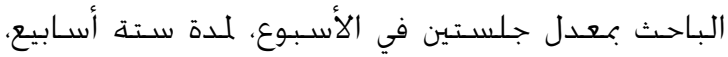

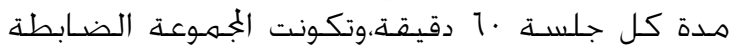

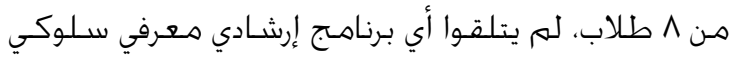

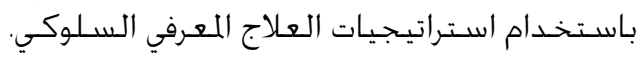

\section{منهج الدراسة: - (20)}

لاختبار صـحة الفـرضـيات، تم استخــدام التصـميم

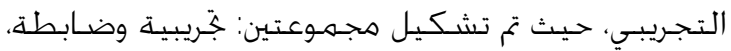

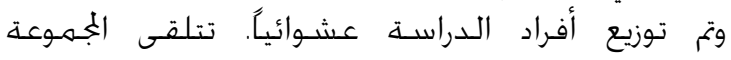

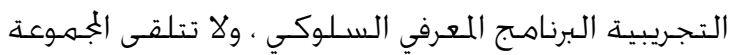

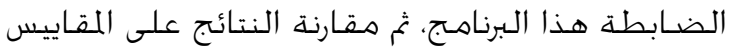

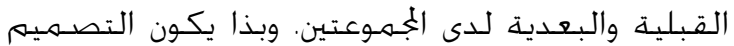
التجريبي كالتالي : التئية

الجـمـوعة التجـريبية: قياس قبلي - الـرنامهج الإرشـادي -

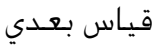

الجمهوعـة الضـابطة: قياس قبلي - عدم التعـرض لأي معالجة - قياس بعدي

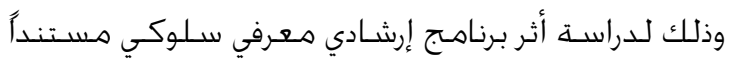

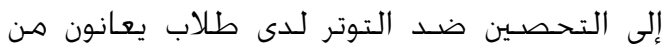

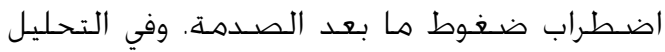
الإحصـائي، تم استخــدام خحليل التباين المشترك

(ANCOVA)

$$
\text { وفيهما يلي ختديد للتغيرات الدراسـة: }
$$

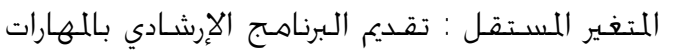

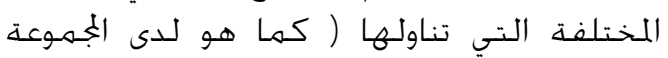

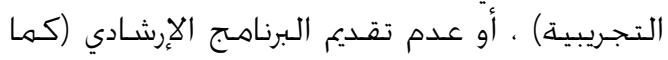
هو لدى العينة الضـابطة ).
قد تفيد في عمليـة الإرشاد والتوجيه النفسي النسي

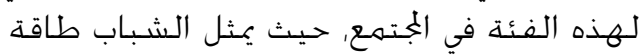

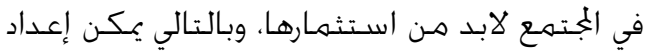

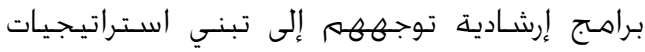

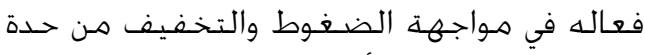

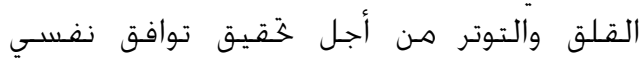

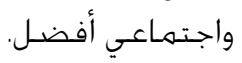

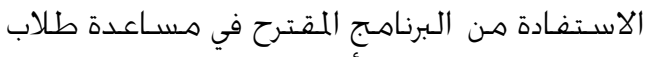

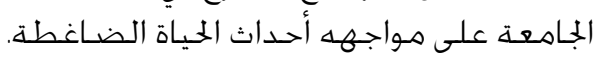

\section{مصطلحات الدراسة:} الإرشاد الجمعي: هو أحسد الأسـاليب الإرشادية التي ماسي

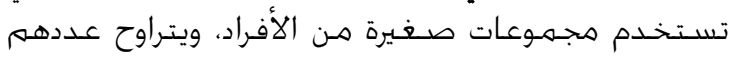

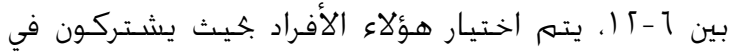

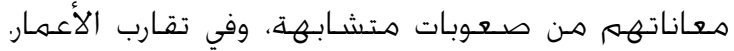

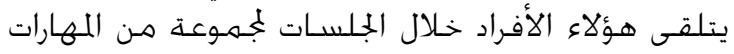

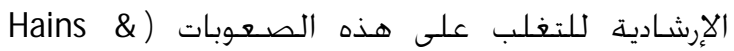

(Szyjakowski, 1990

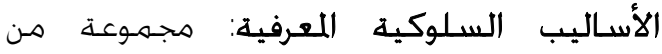

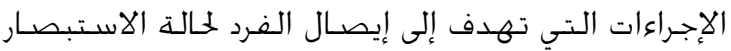

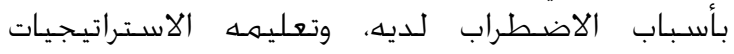

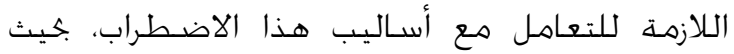

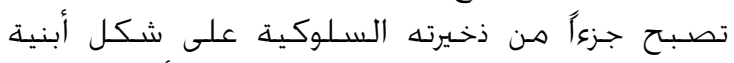

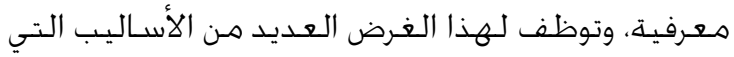

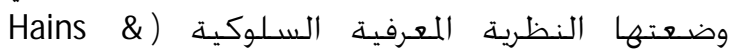

.(Szyjakowski, 1990

التحصين ضـد التوتر: أسـلوب معـرفي سـلوكي

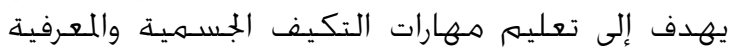

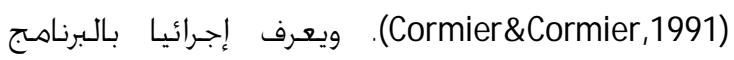

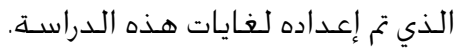

اضطراب ضغوط ما بعد الصـدمة: فئة هـن فئات

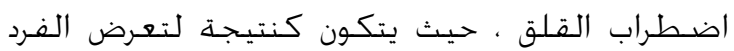

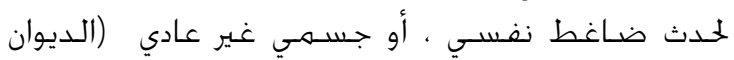

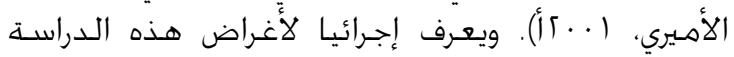

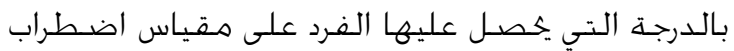

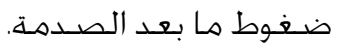

\section{الطريقة و الإجراءات}

\section{مجتمع الدراسة وعينتها:}

تكوّن مجــمع الدراسـة هـن جـميع الطلبة الذين

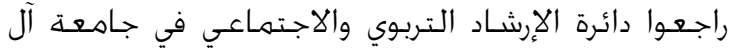

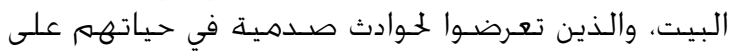

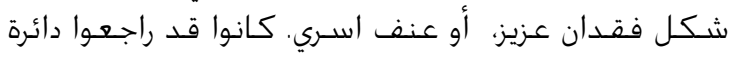

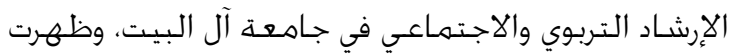

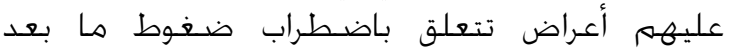


دائماً ولهها خمس درجات، وغالبًا ولهها أربع درجات، وأحياناً

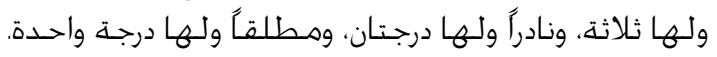

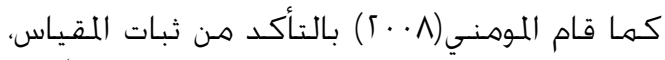

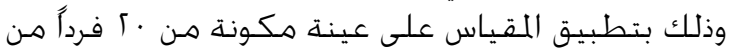

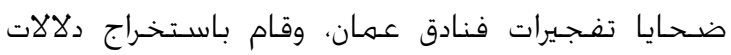

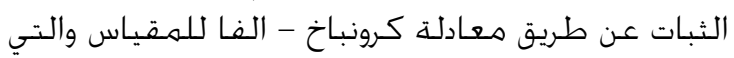

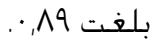

ويته احتساب الدرجة الكلية للمقياس من خلال جمع الدرجات والني تتراوح بين N0- IV على المقياس.

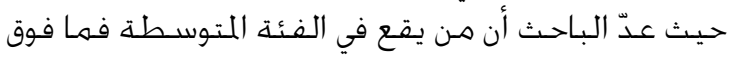
بأنه يعاني من اضطراب ضغوط ما بعد في الصدمة.

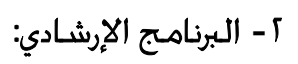

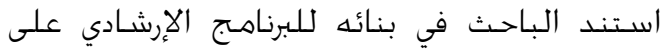

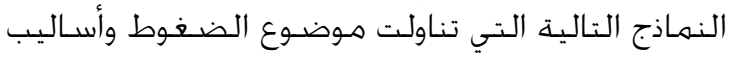

$$
\text { التكيف معها. }
$$

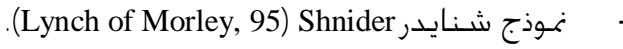
(Roberts of Baumbenger, 99) T.R.E.A.T • البرنامج الإرشادي: برنامج إرشاد جـعـي معرفي سـلوكي

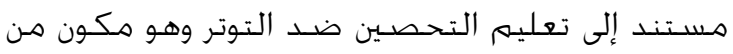

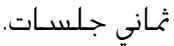

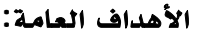

ا - تطوير مهارات الطلبة المشاركين على مواجهة الماجة

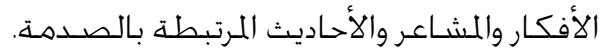
ا - التعبير عن مشـاعر الغضـب دون قلق وتوتر. ب - - تطوير مهارات الطلبة في التعبير عن رغباتهم

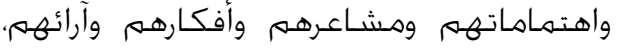
دون مضايقة لأنفسهمه أو للآخرين.

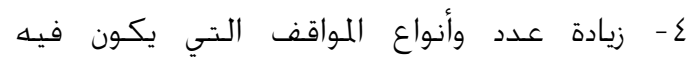

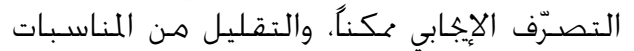

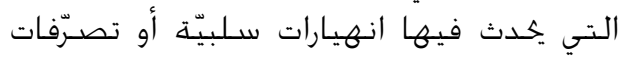
عدوانيّة.

\section{النتائج}

لاستقصاء صحة فرضية الدراسـة، تم استخراج

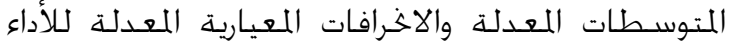

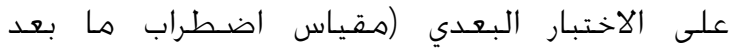

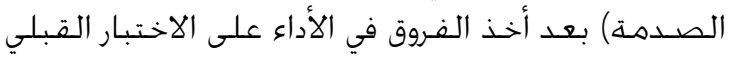
بعين الاعتبار، وجدول ا يبين ذلك.
- المتغير التابع : درجات الأفراد على مقياس اضطراب

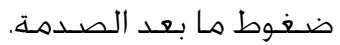

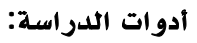

اعتمـدت هذه الدراســة على الأدوات التالية:

I - مقياس اضطراب ضغوط ما بعد الصدمة: تم اختيار Post-traumatic Stress PTSD Checklist مقياس Disorder Check List for special Event

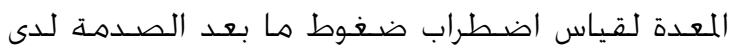

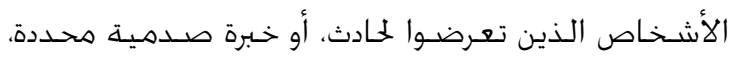
Frank Weathers وهو من إعداد (فرانك ويذرس وزملاؤه)

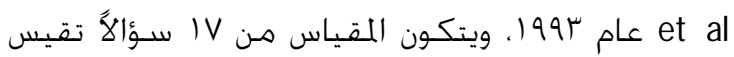

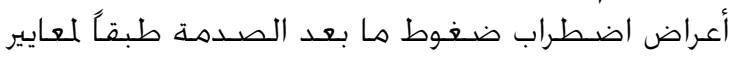

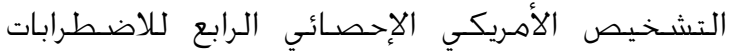

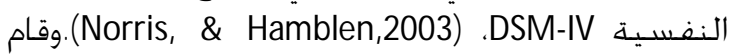

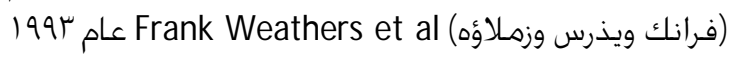

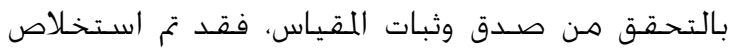

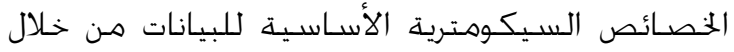

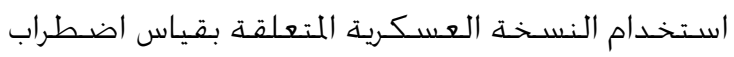

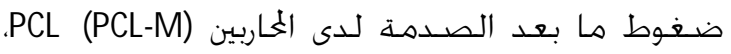

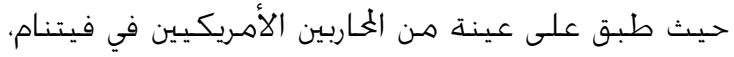

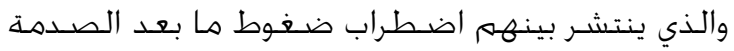
بشكل مرتفع. وقد كان معامل الاتسـاق الداخلي Internal consistency coefficient للدرجة الكلية للمقياس.

وقد وجد بلنشارد، والاسكندر، وبكلي، وفورنيرز Blanchard, Alexander, Buckley \& Forneris (1996)

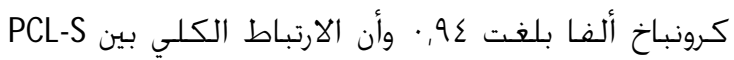

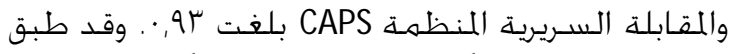

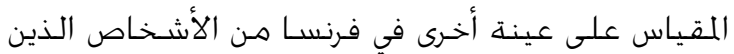

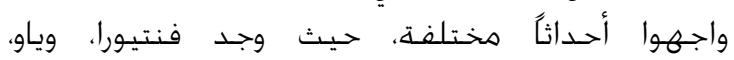

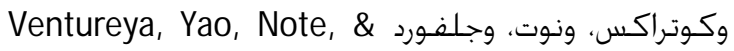
Internal أن معامل الاتسـاق الداخلي Guillard (2002) Consistency

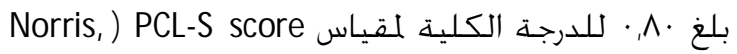
.(Hamblen, 2003

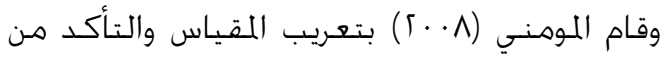

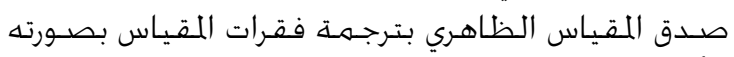

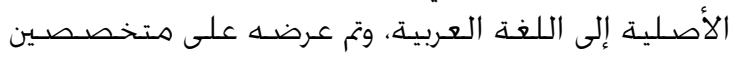

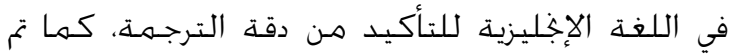

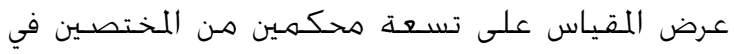

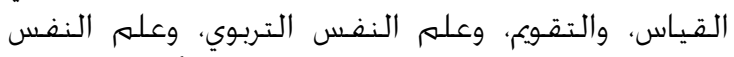

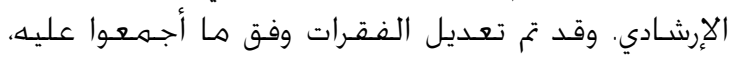

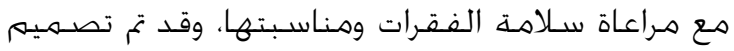

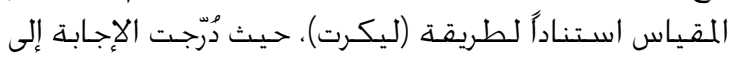




\section{مناقشة النتائج}

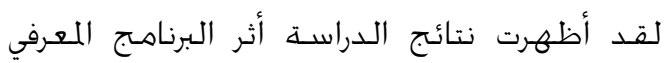

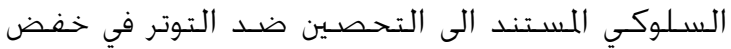

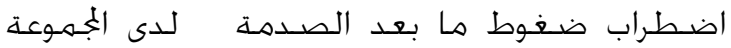

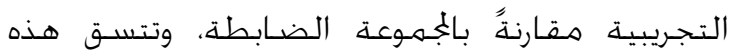
النتيجة بشكل عام مع ما توصلت إليه العديد من هن (Britvic, Radelic \& Urlic, 2006, Hains \& الدراسـات Szyjakowski, 1990, Hains, 1992, Courts, 1991)

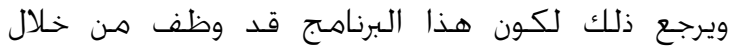

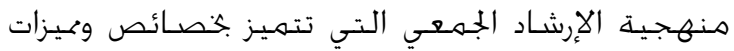

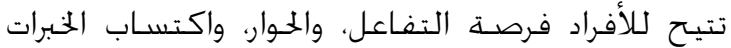

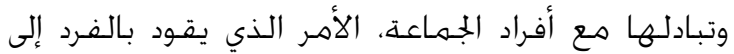

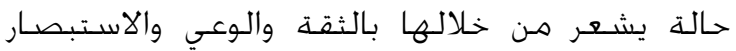

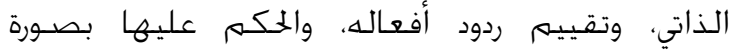

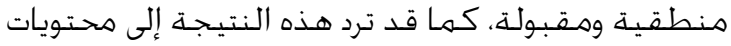

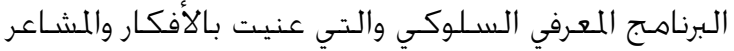

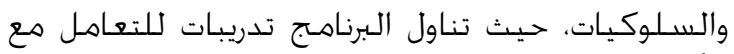

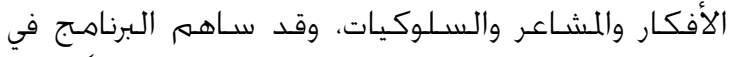

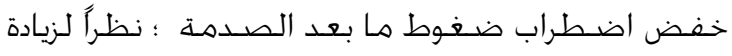

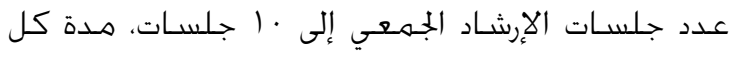

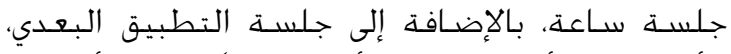

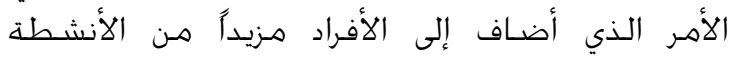

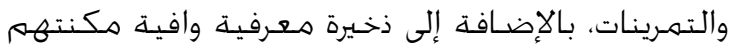

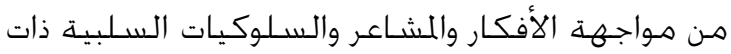

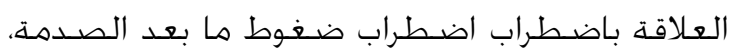

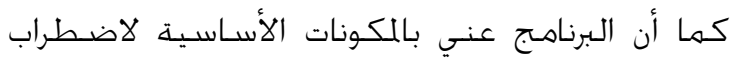

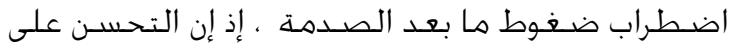

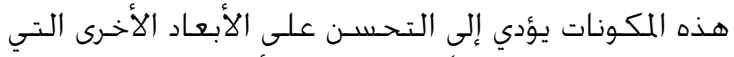

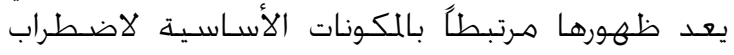

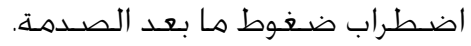

ورما ترد هذه النتيجة إلى أن برنامج التحصين ضد فـد

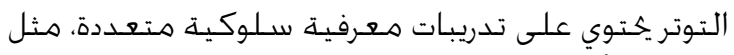

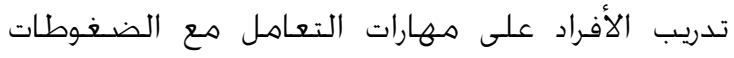

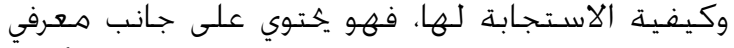

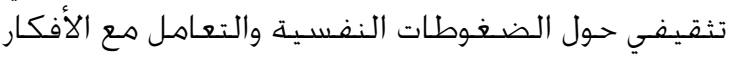

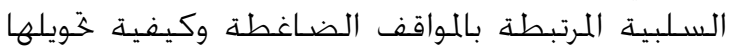
إلى أفكار ايجابية، كما أن البرنامج هدف المافية إلى تدريب

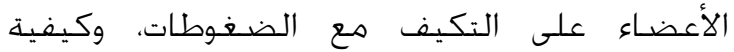

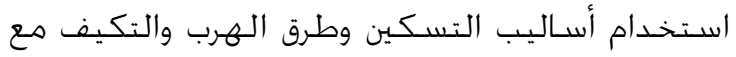
التوتر وتنفيس المشاعر.

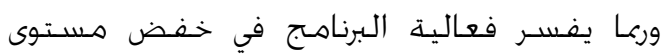

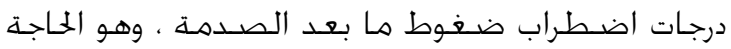

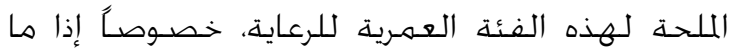

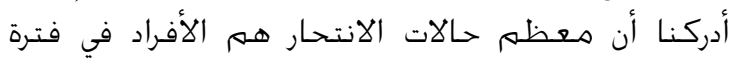

جدول

المتوسط القبلي والبعدي المعدل والانحراف المعياري المعدل لأداء أفراد

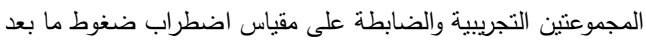

\begin{tabular}{|c|c|c|c|c|}
\hline \multicolumn{5}{|c|}{ الصدمة } \\
\hline \multicolumn{2}{|c|}{ لانحراف المعياري } & \multicolumn{2}{|c|}{ المتوسط المعدل } & \multirow[t]{2}{*}{ لمجموعة } \\
\hline بعدي & قبلي & بعدي & قبلي & \\
\hline$\varepsilon, 7$, & 0,19 & Tr,OHT & $V r, T \leqslant r$ & التجريبية \\
\hline$V, 077$ & $\Lambda, \cdot 1 Y$ & $11 r, 70$. & $\| \leqslant, \leqslant 7$. & الضابطة \\
\hline
\end{tabular}

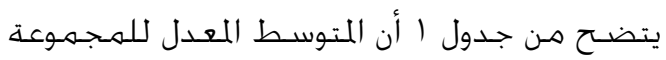

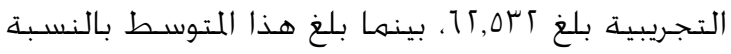

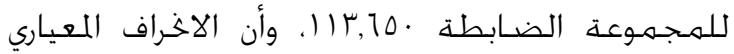

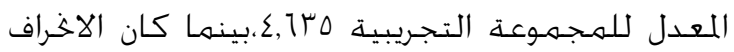

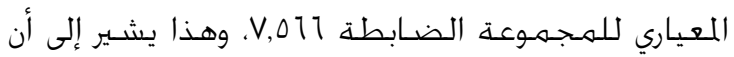

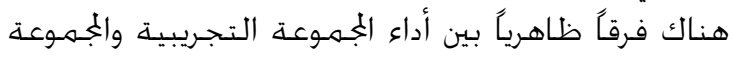

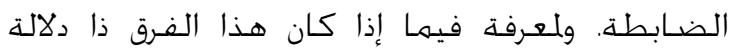

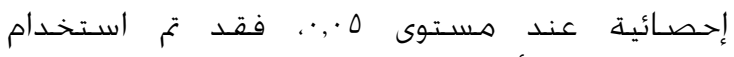

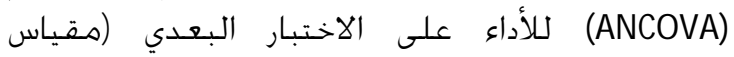

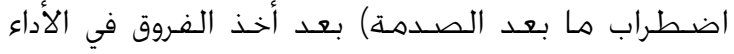

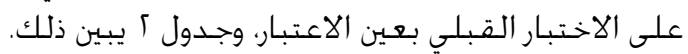

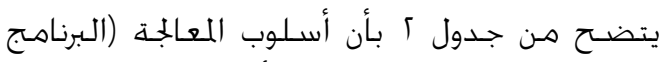

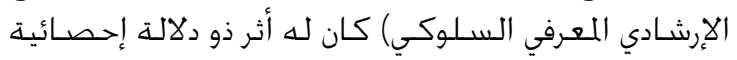

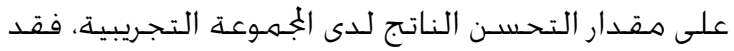

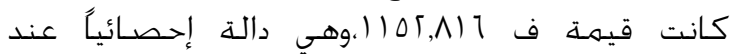

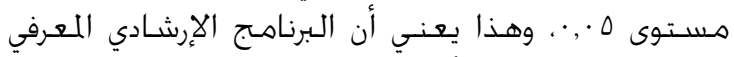

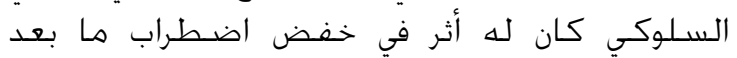

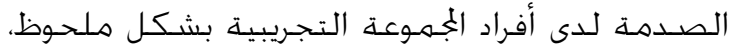

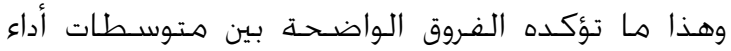

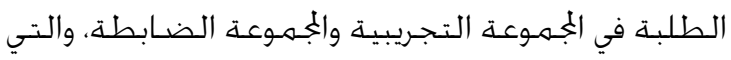

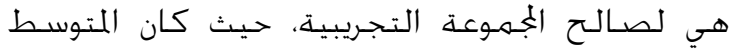

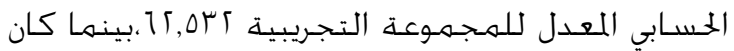

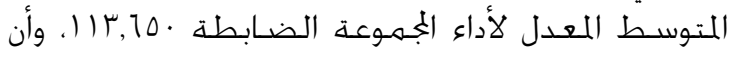

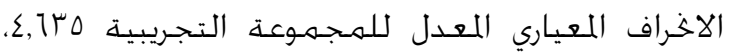

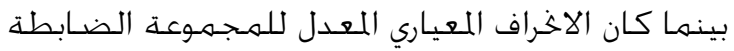

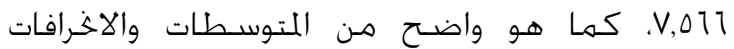

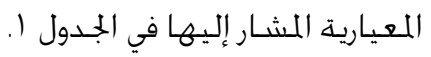

$$
\text { جدول r }
$$

تحليل التباين المصاحب (ANCOVA) على الاختبار البعدي لمقياس اضطراب ضغوط

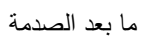

\begin{tabular}{|c|c|c|c|c|c|}
\hline مستوى & قيمة ف & متوسط & المربعات & درجات & التباين \\
\hline$\cdot, \cdots$ & $r r, \Lambda \Lambda$ & $00 \leqslant, 1$. & $00 \leqslant, 1$. & 1 & القبلي \\
\hline$\cdot, \cdots$ & 110r,Ar & אז, אזוגו & אוT & 1 & المعالجة \\
\hline & & $17, \wedge \varepsilon$ & TVV,YO & 11 & الخطاً \\
\hline
\end{tabular}


r - عقد براهـ إرشادية للتوعية بالآثار النفسية

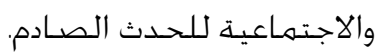

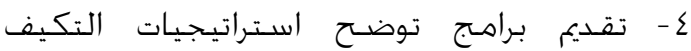
وكيفية الاستفادة هنها.

\section{المـراجع}

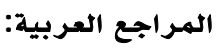

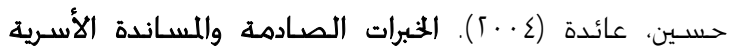

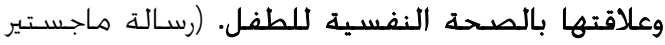

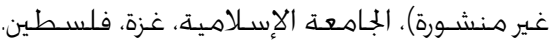

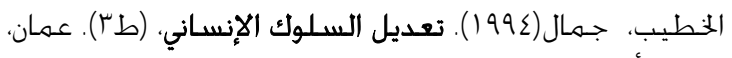
الأردن: دار حنـين للنشـر والتوزيع.

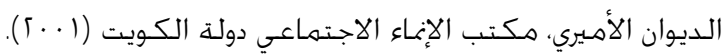

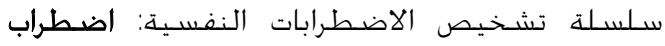

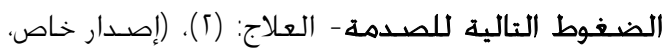

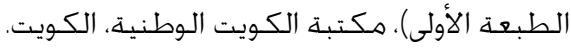

عبد الستار، إبراهيم (99^()). الاكتئاب: اضطرابات العصر

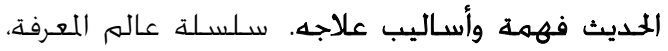

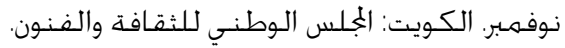

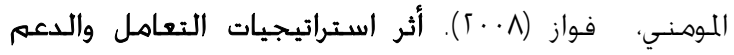

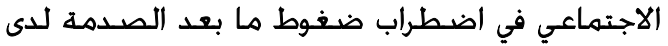

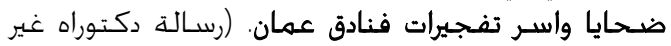
منشـورة)، الجامعة الأردنية، الأردن.
الشـباب، للا يواجهونه هـن ضغوطات نفسية متكررة

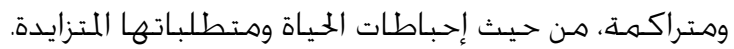
وقـد ترجع فاعلية البرنامج الإرشـادي إلى أنه يقلـل هـن

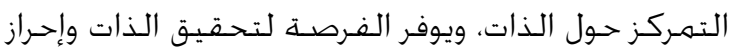

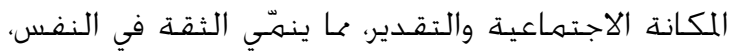

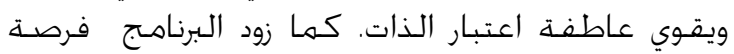

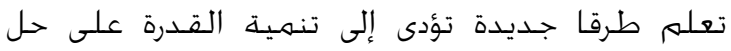

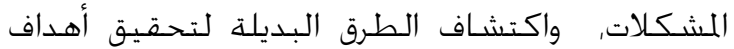

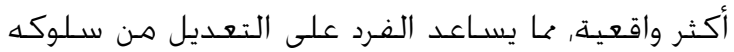

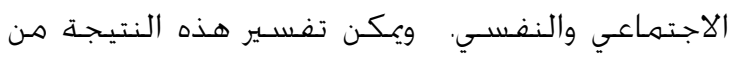

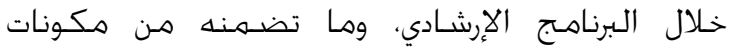

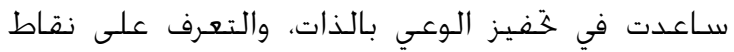

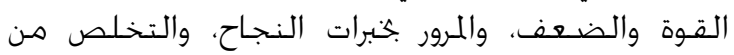

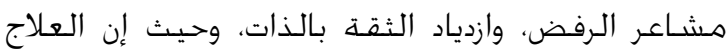

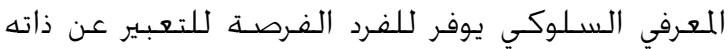

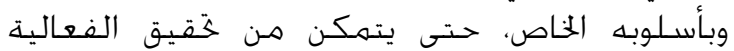
والجـدارة.

وربما ترد هذه النتيجـة إلى ما تضـمـنه البرناهـج هـن

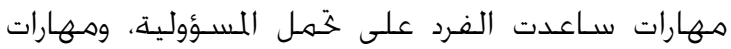

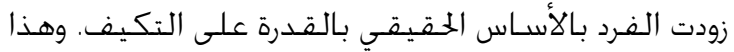

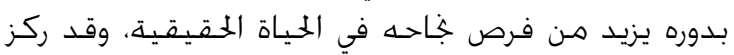

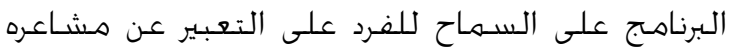

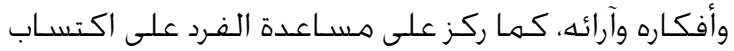

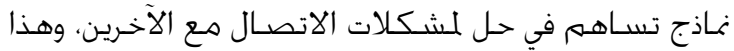

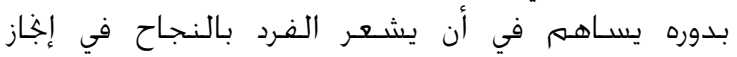

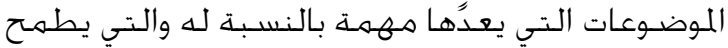

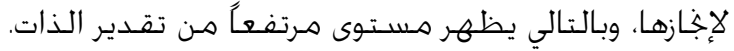

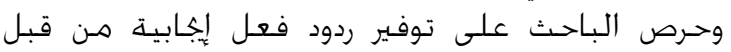

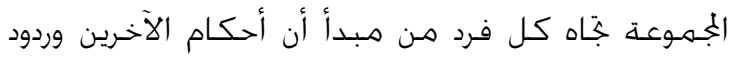

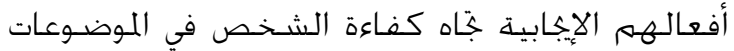

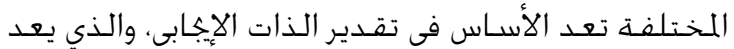

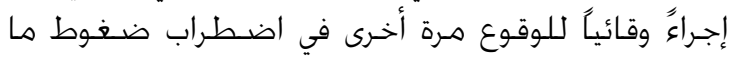
بعد الصندمة. وقيأ.

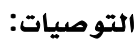

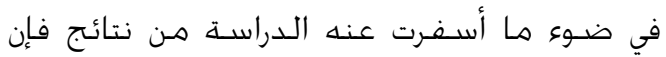
الباحـث يقترح التوصـيات الآتيـة:

I - إعـداد برامـج جامعية تهدف إلى زيادة القـدرة على

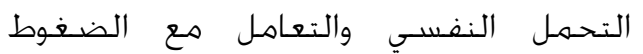

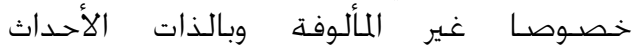
الصدمية.

؟ - إنشاء مراكز متخصهـة لضحايا الكوارث

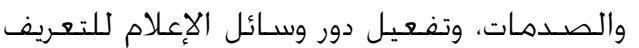

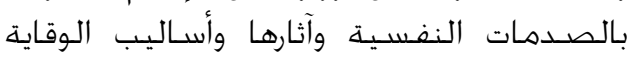

sis 


$$
\text { المر اجـع الاجنبية: }
$$

Ahmad, A., Sofi, M., Sundelin - Wahlsten, V. \& Von Knoring, A. (2000). Posttraumatic stress disorder in children after the military operation "Anfal" in Iraqi Kurdistan. European Child \& A dolescent Psychiatry, 9(1) 235-243.

Aldwin, C. \& Levenson, M. (2004). Posttraumatic growth: A developmental perspective Psychological Inquiry, 15(2) 19-22.

American Psychiatric Association.(1994). Diagnostic and Statistical M anual of M ental Disorders, (4th ed.). DSM-IV. Washington, DC: A uthor.

Becky, C. (2002). N ew treatment of post traumatic stress disorder. Retrieved from: www.f.le.comp/7/f/N ewtreatmentof PTSD htm.

Beers, S. \& De Bellis, M. (2002). Neuropsychological function in children with maltreatment-related post- Traumatic stress disorder. American Journal of Psychiatry, 15(9) 483-486.

Bober, T. \& Regehr, C. (2006). Strategies for reducing secondary or vicarious trauma: Do they work? Journal of Brief Treatment and Crisis Intervention, 6(1) 1-9.

Brewin, C. \& Holmes, E. (2003). Psychological theories of posttraumatic stress disorder. Clinical Psychological Review, 23(2) 339-376.

Britvic, D., Radelic, N., \& Urlic, I. (2006). Long term dynamic-oriented group psychotherapy posttraumatic stress disorder in war veterans: Prospective study of five-year treatment. Croat M ed Journal, 47 (1) 67-84. Retrieved January 2, 2008, from Pub Med.

Cloitre, M., Koenen, K., Cohen, L. \& Han, H. (2002).Skills training in affective and interpersonal regulation followed by exposure: A phase - based treatment for PTSD related to childhood abuse. Journal of Consulting and Clinical Psychology, 70(1) 10671074.

Cormier, S. \& Cormier, B. (1991) (2nd Edition). Interviewing strategies for helpers, fundamental skills and cognitive behavioral interventions. California: Brooks.

Courts, N. (1991). Stress inoculation education and counseling with patients on hemodialysis: effects on psychosocial stressors and adherence Journal of Consulting and Clinical Psychology, 8(2)125-144.

Dubner, A. \& Motta, R. (1999). Sexually and physically abuse foster care children and posttraumatic stress disorder. Journal of Consulting and Clinical Psychology, 67(2) 367373.
Enda, B. (1999). A comparison of Exposure therapy, stress inoculation training, and their combination for reducing posttraumatic stress disorder in female assault victims. Journal of Consulting and Clinical Psychology, 67 (2) 194 200.

Gagnon,M. \& Ladouceur, R. (1992).Behavioral treatment of child stutters: replication and extension. Behavior Therapy, 23(2) 113-129.

Hains, A. (1992). A Stress inoculation training program for adolescents in a high school setting: a multiple baseline approach. Journal of A dolescents, 15 (2) 163-175.

Hains, A. \& Szyjakowski, G. (1990). Stress Inoculation Training. Journal of Adolescents, 18(1)111-128.

Hersen M. \& Bellack A. (1985). Handbook of Clinical Behavior Therapy with Adults. (1st Ed.). New York: Plenum Press.

Hunter, M. (2003). Cognitive behavioral interventions for premenstrual and menopausal problems. Infant Psychology, 21(2) 183-194.

Lynch, R., Morley, K. \& Kathleen,L. (1995). Adaptation to pediatric physical disability within the family system: a conceptual model for counseling families. Family Journal, 3(3)207218.

March, J. (1998). Cognitive-behavioral psychotherapy for children and adolescents with posttraumatic stress disorder after a single-incident stressor. Journal of the American A cademy of child and A dolescent Psychiatry, 37(2) 585-593.

Meichenbaum, D. (1996). Stress inoculation training for coping with stressors, The Clinical Psychologist, 49(1) 4-7.

Murphy, A., Lehrer, P., \& Jurish, S. (1990). Cognitive coping skills training and relaxation training as treatments for tension headaches. Behavior Therapy, 21(3) 89-98.

Nicholson, N. \& Blanchard, E. (1993). A controlled evaluation of behavioral treatment of chronic headache in the elderly. B ehavior Therapy, 24(2) 395-408.

Norris, F. \& Hamblen, J. (2003). Standardized self-report measure of civilian trauma and PTSD. In J. Wilson \& T. Keane. (Eds.), Assessing psychological trauma and PTSD: A practitioner's handbook (2nd Ed.), New York: Guilford.

Ponniah, K. \& Hollon, S.(2009). Empirically supported psychological treatments for adult acute stress disorder and posttraumatic stress 
disorder. Journal of Depression, 26(12) 10861109.

Roberts, R. \& Baumberger, J. (1999). T.R.E.A.T. a model for Constructing Counseling and objectives for students with special needs. Intervention in School \& Clinic, 34( 4) 239-245.

Tucker, P. \& Trautman, R.(2000). Understanding and treating Past, present, and future, Bulletin of Menninger Clinic, 44(64) 3751. Retrieved January 2, 2008, from PubM ed.

Voges, M. \& Romney, D. (2003). Risk and resiliency factors posttraumatic stress disorder, A nn Gen
Hosp Psychiatry, Doi: 10.1186/ 1475-2832-2-4. Retrieved January 2, 2008, from PubMed.

Yeong-Yuh, L. \& Chia, S. (2001). Phenomenology of obsessive-compulsive disorder in Taiwan. Psychiatry and Clinical N eurosciences, 55(5) 623627.

Yule, W. \& Canterbury, R. (1994).The treatment of post traumatic stress disorder in children and adolescents. International Review of Psychiatry, 6 (3) 141-149. 